American Journal of Applied Sciences 6 (5): 987-994, 2009

ISSN 1546-9239

(C) 2009 Science Publications

\title{
A GA Based Transmission Network Expansion Planning Considering Voltage Level, Network Losses and Number of Bundle Lines
}

\author{
${ }^{1}$ S. Jalilzadeh, ${ }^{2} \mathrm{H}$. Shayeghi, ${ }^{1}$ M. Mahdavi and ${ }^{1} \mathrm{H}$. Hadadian \\ ${ }^{1}$ Department of Technical Engineering, Zangan University, Zanjan, Iran \\ ${ }^{2}$ Department of Technical Engineering, University of Mohaghegh Ardabili, Ardabil, Iran
}

\begin{abstract}
Transmission Network Expansion Planning (TNEP) was studied considering voltage level, network losses and number of bundle lines using decimal codification based genetic algorithm (DCGA). TNEP determines the characteristic and performance of the future electric power network and directly influences the operation of power system. Up till now, various methods have been presented for the solution of the Static Transmission Network Expansion Planning (STNEP) problem. However, in all of these methods, STNEP problem has been solved regardless of voltage level of transmission lines. For this reason and according to various voltage levels and different number of bundle lines used in real transmission network which caused different annual losses, STNEP was studied considering voltage level, network losses and number of bundle lines using genetic algorithm. Genetic Algorithms (GAs) have demonstrated the ability to deal with non-convex, nonlinear, mixedinteger optimization problems, like the TNEP problem, better than a number of mathematical methodologies. The proposed method was tested on an actual transmission network of the Azerbaijan regional electric company, Iran, to illustrate its robust performance. The results were shown that considering the network losses in a network with different voltage levels and the number of bundle lines considerably decreased the operational costs and the network can be satisfied the requirement of delivering electric power more safely and reliably to load centers.
\end{abstract}

Key words: Transmission network expansion planning, bundle lines, genetic algorithms, voltage level

\section{INTRODUCTION}

Transmission Network Expansion Planning (TNEP) is a basic part of power system planning that determines where, when and how many new transmission lines should be added to the network. It minimizes the network construction and operational cost while meeting imposed technical, economic and reliability constraints. TNEP should be satisfied required adequacy of the lines for delivering safe and reliable electric power to load centers during the planning horizon ${ }^{[1-3]}$. Calculation of investment cost for network expansion is difficult because it is dependent on the various reliability criteria ${ }^{[4]}$. Thus, the long-term TNEP is a hard, large-scale combinatorial optimization problem. Transmission network expansion planning can be classified as static or dynamic. Static expansion determines where and how many new transmission lines should be added to the network during the planning horizon. If in the static expansion the planning horizon is categorized in several stages we would have dynamic planning ${ }^{[5,6]}$.
In the majority of power systems, generating plants are located far from the load centers. In addition, the planned new projects are still far from completion. Due to these factors, investment cost for transmission network is huge. Thus, the STNEP problem acquires a principal role in power system planning and should be evaluated carefully because any effort to reduce transmission system expansion cost significantly improves cost saving. After Garver's paper that was published in $1970^{[7]}$, much research has been done on the field of TNEP problem. Some of this researches such as ${ }^{[1-3,6,6-24]}$ were related to problem solution method. Some others proposed different approaches for solution of this problem considered various parameters such as uncertainty in demand ${ }^{[5]}$, reliability criteria $^{[4,25,26]}$ and economic factors ${ }^{[27]}$. Also, some of them investigated this problem and generation expansion planning together ${ }^{[28,29]}$. Recently, different methods such as GRASP ${ }^{[3]}$, Bender decomposition ${ }^{[6]}$, HIPER $^{[17]}$ branch and bound algorithm ${ }^{[30]}$, sensitivity analysis $^{[15]}$, genetic algorithm ${ }^{[1,11,20,24]}$, simulated annealing ${ }^{[16]}$ and Tabu search ${ }^{[12]}$ have been proposed for

Corresponding Author: Hossein Shayeghi, Department of Technical Engineering, University of Mohaghegh Ardabili, P.O. Box: 179, Ardabil, Iran 
solution of the STNEP problem. In all of them, the problem has been solved regardless of voltage level of transmission lines and the role of voltage level in reducing network annual losses. $\operatorname{In}^{[8]}$, authors proposed a neural network based method for the solution of the TNEP problem through considering the network losses and lines construction cost. But the role of lines voltage level and related substations cost have not been investigated in this study. $\operatorname{I~}^{[10]}$, the network expansion costs and transmitted power through the lines have been included in objective function and the goal was optimization of both expansion costs and lines loading. In addition, the objective function was different from those which were considered in ${ }^{[6,11,12,15-17,20,24,30]}$, but the voltage level of transmission lines, network losses and bundle of lines have not been investigated. $\operatorname{In}^{[31]}$, the voltage level of transmission lines has been considered as an additional factor, but the proposed objective function only includes expansion and generation costs and one of the reliability criteria i.e.: power not supplied energy. Moreover, expansion planning has been studied as dynamic type and the network losses have not been considered.

In this study, according to various voltage levels and different number of bundle lines used in transmission network which cause different annual losses, STNEP was studied considering voltage level, network losses and number of bundle lines using decimal codification genetic algorithm. Moreover, the lines network losses cost and the expansion cost of related substations from the voltage level point of view was included in the objective function. The considered voltage levels for TNEP problem in this research are 230 and $400 \mathrm{kV}$. These voltages are extendable to another voltage levels, too. The proposed method was tested on a real transmission network of the Azerbaijan regional electric company in order to demonstrate the effectiveness of the proposed idea. This network has been located in northwest of Iran.

\section{MATERIALS AND METHODS}

The STNEP problem is a mixed-integer nonlinear optimization problem. Due to considering voltage level of lines in transmission network expansion planning and subsequent expansion cost of substations, the proposed objective function was defined as follows:

$$
\begin{gathered}
\mathrm{C}_{\mathrm{T}}=\sum_{\mathrm{i}, \mathrm{j} \in \Omega} \mathrm{CL}_{\mathrm{ij}} \mathrm{n}_{\mathrm{ij}}+\sum_{\mathrm{k} \in \Psi} \mathrm{CS}_{\mathrm{k}}+\sum_{\mathrm{i}=1}^{\mathrm{NY}} \mathrm{C}_{\text {loss }} \\
\mathrm{C}_{\text {loss }}=\operatorname{loss} \times \mathrm{C}_{\mathrm{MWh}} \times \mathrm{k}_{\text {loss }} \times 8760
\end{gathered}
$$

$$
\text { loss }=\sum_{\mathrm{i}, \mathrm{j} \in \Omega} \mathrm{R}_{\mathrm{ij}} \mathrm{I}_{\mathrm{ij}}{ }^{2}
$$

Where:

$\mathrm{C}_{\mathrm{T}} \quad=$ Total expansion cost of network

$\mathrm{CL}_{\mathrm{ij}}=$ Construction cost of each line in branch $\mathrm{i}-\mathrm{j}$ (it is different for 230 and $400 \mathrm{KV}$ lines)

$\mathrm{CS}_{\mathrm{k}}=$ Expansion cost of $\mathrm{k}^{\text {th }}$ substation

$\mathrm{C}_{\text {loss }}=$ Annual losses cost of network

Loss $=$ Total losses of network

$\mathrm{C}_{\mathrm{MWh}}=$ Cost of one MWh (\$US/MWh)

$\mathrm{k}_{\text {loss }}=$ Losses coefficient

$\mathrm{n}_{\mathrm{ij}} \quad=$ Number of all new circuits in corridor $\mathrm{i}-\mathrm{j}$

$\mathrm{R}_{\mathrm{ij}} \quad=$ Resistance of branch $\mathrm{i}-\mathrm{j}$

$\mathrm{I}_{\mathrm{ij}} \quad=$ Flow current of branch $\mathrm{i}-\mathrm{j}$

$\Omega \quad=$ Set of all corridors

$\Psi \quad=$ Set of all substations

$\mathrm{NY}=$ Expanded network adequacy (in year)

The calculation method of $\mathrm{k}_{\mathrm{loss}}$ and $\mathrm{CS}_{\mathrm{k}}$ was given in $^{[32]}$. It should be mentioned that the network losses is calculated through performing DC load flow based on the network load growth factor for years after expansion horizon.

Several restrictions have to be modeled in a mathematical representation to ensure that the mathematical solutions are in line with the planning requirements. These constraints are as follows ${ }^{[5,24]}$ :

$$
\begin{gathered}
\text { Sf }+g-d=0 \\
f_{i j}-\gamma_{i j}\left(n_{i j}^{0}+n_{i j}\right)\left(\theta_{i}-\theta_{j}\right)=0 \\
\left|f_{i j}\right| \leq\left(n_{i j}^{0}+n_{i j}\right) \overline{f_{i j}} \\
0 \leq n_{i j} \leq \overline{n_{i j}} \\
0 \leq \mathrm{g} \leq \mathrm{g}
\end{gathered}
$$

$$
\text { Line_Loading } \leq \mathrm{LL}_{\max }
$$

Where (i, j) $\in \Omega$ and:

$\mathrm{S}=$ Branch-node incidence matrix

$\mathrm{f}=$ Active power matrix in each corridor

$\mathrm{g}=$ Generation vector

$\mathrm{d}=$ Demand vector

$\theta=$ Phase angle of each bus

$\gamma_{i j}=$ Total susceptance of circuits in corridor $i-j$

$\mathrm{n}_{\mathrm{ij}}^{0}=$ Number of initial circuits in corridor $\mathrm{i}-\mathrm{j}$

$\overline{n_{i j}}=$ Maximum number of constructible circuits in corridor $\mathrm{i}-\mathrm{j}$ 


$$
\begin{aligned}
& \overline{\mathrm{g}} \quad=\text { Generated power limit in generator } \\
& \overline{\mathrm{f}_{\mathrm{ij}}} \quad=\text { Maximum of transmissible active } \\
& \text { power through corridor } \mathrm{i}-\mathrm{j} \text { which will } \\
& \text { have two different rates according to } \\
& \text { voltage level of candidate line } \\
& \text { Line_Loading }=\text { Loading of lines at planning horizon } \\
& \text { year and start of operation time } \\
& \mathrm{LL}_{\max } \quad=\text { Maximum loading of lines at } \\
& \text { planning horizon year }
\end{aligned}
$$

In this study, the objective function was different from those which were considered in ${ }^{[1-20,23-27,29,30]}$ and in part of the problem constraints, $\overline{\mathrm{f}_{\mathrm{ij}}}$ is considered as an additional constraint. In addition to the abovementioned changes, also Line_Loading constraint was considered as a new constraint in order to ensure adequacy of the network after expansion. It should be noted that $\mathrm{LL}_{\max }$ is an experimental parameter determined according to the load growth coefficient and its rate is between 0 and 1 . Added lines to the network, network adequacy (increasing of overload duration time) and expansion cost are increased with reducing rate of this parameter. Also, network losses and lines loading is decreased.

\section{PROPOSED SOLUTION ALGORITHM}

The goal of the STNEP problem is to obtain the number of lines and their voltage level to expand the transmission network in order to ensure required adequacy of the network during the specific planning horizon. Thus, problem parameters of the problem are discrete time type and consequently the optimization problem is an integer programming problem. To solve of this problem, there are various methods such as classic mathematical and heuristic methods ${ }^{[5-21]}$. In this study, the decimal codification genetic algorithm is used for the solution of the STNEP problem due to flexibility, simple implementation and the advantages mentioned $\mathrm{in}^{[11]}$. In the proposed method, expansion and completion of objective function (for example, adding the network losses, changing studied voltage levels to another levels and etc) would be practicable.

Decimal codification genetic algorithm and chromosome structure of the problem: Standard genetic algorithm is a random search method that can be used to solve non-linear system of equations and optimize complex problems. The base of this algorithm is the selection of individuals. It doesn't need a good initial estimation for the sake of problem solution, In other words, the solution of a complex problem can be started with weak initial estimations and then be corrected in evolutionary process of fitness.

The standard genetic algorithm manipulates the binary strings which may be the solutions of the problem. This algorithm can be used to solve many practical problems such as transmission network expansion planning. The genetic algorithm generally includes the three fundamental genetic operators of reproduction, crossover and mutation. These operators are used to find better fitness function.

There are three methods for coding the transmission lines based on the genetic algorithm method $^{[11]}$ :

- Binary codification for each corridor

- Binary codification with independent bits for each line

- Decimal codification for each corridor

Although binary codification is conventional in genetic algorithm but in here, the third method has been used due to the following reasons:

- Avoiding difficulties which occure at coding and decoding the problem

- Preventing the production of completely different offspring from their parents and subsequent occurrence of divergence in the mentioned algorithm

In this method, crossover can take place only at the boundary of two integer numbers. Mutation operator selects one of existed integer numbers in chromosome and then changes its value randomly. Reproduction operator, similar to standard form, reproduces each chromosome proportional to the value of its objective function. Therefore, the chromosomes which have better objective functions will be selected more probably than other chromosomes for the next population (i.e., Elitism strategy). Consequently, the selected chromosome considering voltage level and bundle of lines and also simplicity in programming was divided into the following parts as shown in Fig. 1. In part 1, each gene includes number of existed circuits (both of constructed and new circuits) in each corridor. Genes of part 2 and part 3 describe voltage levels and number of corresponding bundle lines of existed genes in part 1. It should be noted that the binary digits of 0 and 1 have been used for representing voltage levels of 230 and $400 \mathrm{kV}$, respectively. If other voltage levels exist in the network, the numbers 2, 3 and etc., can be used for representing them in the genes of part 2 . Therefore, the 
Am. J. Applied Sci., 6 (5): 987-994, 2009

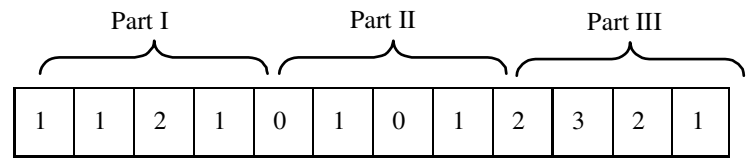

Fig. 1: Typical chromosome structure

proposed coding structure would be extendable to other voltage levels. A typical chromosome for a network with 4 corridors is shown in Fig. 1. In the first corridor, one $400 \mathrm{kV}$ transmission circuit with one bundle, in the second corridor, two $230 \mathrm{kV}$ transmission circuits with two bundle conductors, in the third corridor, three 400 $\mathrm{kV}$ transmission circuit with one bundle conductor and finally in the forth corridor, two $230 \mathrm{kV}$ transmission circuit with one bundle conductor have been predicted. The flowchart of the proposed method for the solution of the STENP problem is shown in Fig. 2.

Selection, crossover and mutation process: Selection operator selects the chromosome in the population for reproduction. The more fit the chromosome, the higher its probability of being selected for reproduction. Thus, selection is based on the survival-of-the-fittest strategy, but the key idea is to select the better individuals of the population, as in tournament selection, where the participants compete with each other to remain in the population. The most commonly used strategy to select pairs of individuals that has applied in this study is the method of roulette-wheel selection, in which every string is assigned a slot in a simulated wheel sized in proportion to the string's relative fitness. This ensures that highly fit strings have a greater probability to be selected to form the next generation through crossover and mutation. After selection of the pairs of parent strings, the crossover operator is applied to each of these pairs.

The crossover operator involves the swapping of genetic material (bit-values) between the two parent strings. Based on predefined probability, known as crossover probability, an even number of chromosomes are chosen randomly. A random position is then chosen for each pair of the chosen chromosomes. The two chromosomes of each pair swap their genes after that random position. Crossover may be applied at a single position or at multiple positions. In this work, because of choosing smaller population multiple position crossovers are used with probability of 1. Each individuals (children) resulting from each crossover operation will now be subjected to the mutation operator in the final step to forming the new generation. The mutation operator enhances the ability of the GA to find a near optimal solution to a given problem by

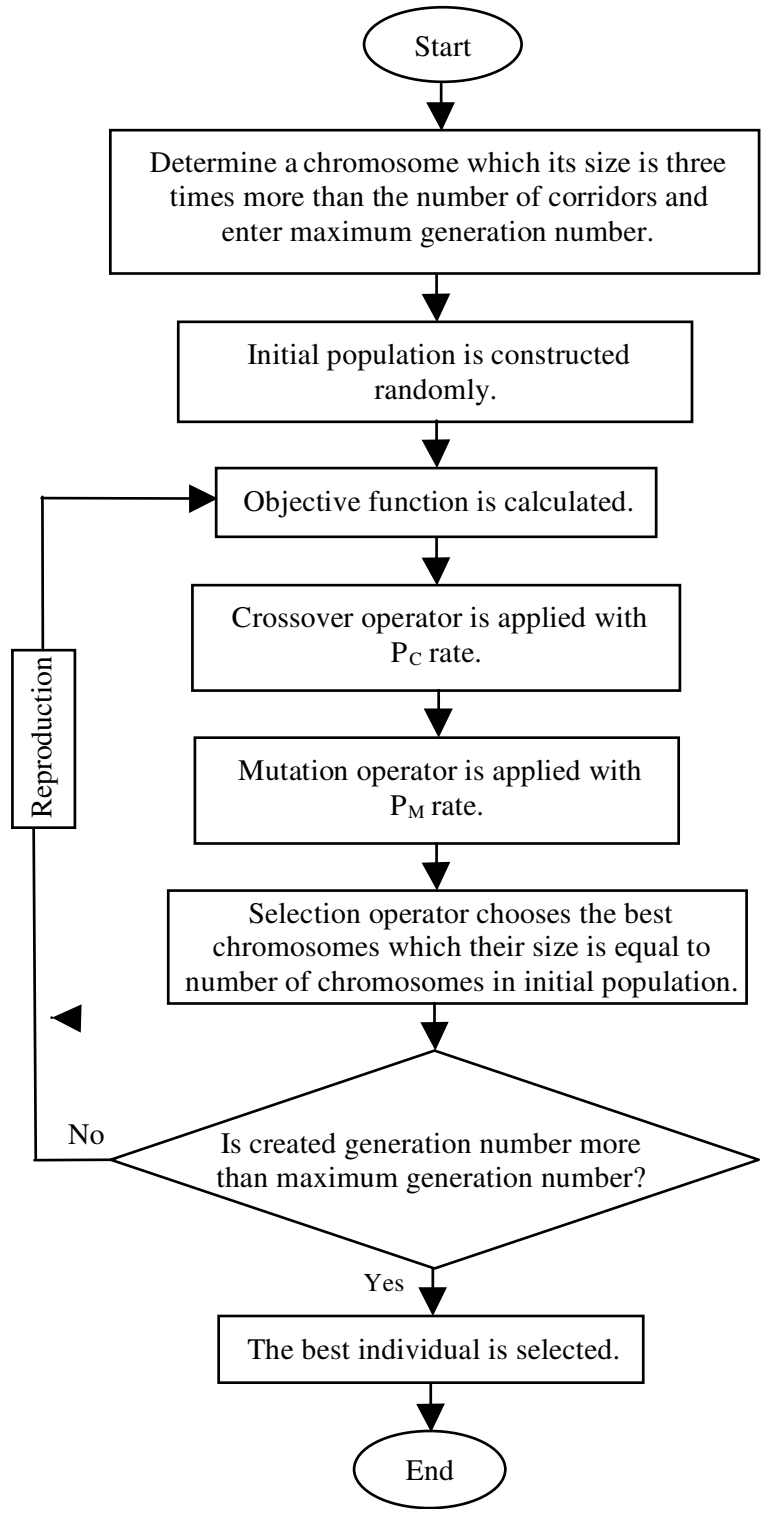

Fig. 2: Flowchart of the proposed method

maintaining a sufficient level of genetic variety in the population, which is needed to make sure that the entire solution space is used in the search for the best solution. In a sense, it serves as an insurance policy; it helps prevent the losses of genetic material. This operator randomly flips or alters one or more bit values usually with very small probability known as a mutation probability (typically between 0.001 and 0.01 ). In a binary coded GA, it is simply done by changing the gene from 1 to 0 or vice versa. In DCGA, as in this study, the gene value was randomly increased or decreased by 1 without crossing its limits. Practical 
experience has shown that in the transmission expansion planning application the rate of mutation has to be larger than ones reported in the literature for other application of the GA. Here, mutation was used with probability of 0.01 per bit.

After mutation, the production of new generation is completed and it is ready to start the process all over again with fitness evaluation of each chromosome. The process continues and it is terminated by either setting a target value for the fitness function to be achieved, or by setting a definite number of generations to be produced. In this study, a more suitable criterion termination was employed, that is, the production of predefined generations after obtaining the best fitness and finding no better solution. In this study, the maximum number of generations is considered 1500 .

\section{RESULTS AND DISCUSSION}

The transmission network of the Azerbaijan regional electric system was used to test the proposed method. This actual network has been located in northwest of Iran and is shown in Fig. 3. The system data and construction costs of 230 and $400 \mathrm{kV}$ lines are listed in Table 1-7. In order to evaluate effects of the

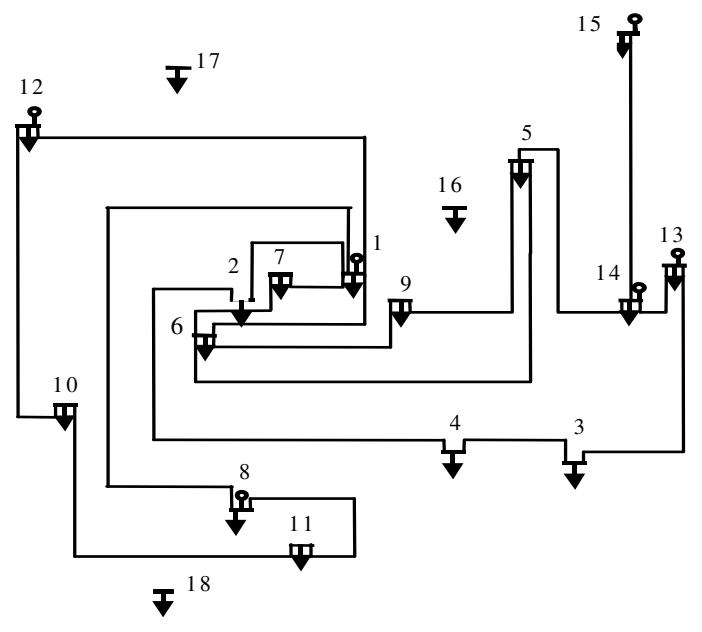

Fig. 3: Transmission network of the Azerbaijan regional electric company

Table 1: Arrangement of substations

\begin{tabular}{llll}
\hline Substation & Voltage level $(\mathrm{kV})$ & Substation & Voltage level $(\mathrm{kV})$ \\
\hline 1 & $400 / 230$ & 10 & $230 / 132$ \\
2 & $230 / 132$ & 11 & $230 / 132$ \\
3 & $400 / 230$ & 12 & $230 / 132$ \\
4 & $230 / 63$ & 13 & $230 / 63$ \\
5 & $230 / 132$ & 14 & $400 / 230$ \\
6 & $230 / 132$ & 15 & $230 / 63$ \\
7 & $230 / 132$ & 16 & $230 / 20$ \\
8 & $230 / 132$ & 17 & $230 / 132$ \\
9 & $230 / 132$ & 18 & $230 / 132$ \\
\hline
\end{tabular}

network losses and planning horizon year on an actual transmission network, the proposed method was applied to this test network and the results (lines which should be added to the network during the planning horizon year) were shown in Table 8 and 10. Also, Table 9 and 11 showed the expansion costs. The first and second configurations are obtained ignoring and considering the network losses, respectively.

Total expansion cost (sum of expansion and losses costs) of expanded network with the two proposed configurations was shown in Fig. 4. Process of investment return for this configuration in comparison with the first one was depicted in Fig. 5. In fact, this curve is equal to subtraction of cost curves of two mentioned configurations in Fig. 4.

According to Fig. 4, it can be seen that the start point of second curve is upper than start point of first curve on the vertical axis, but this curve cuts the first curve about 4 years after planning horizon (year 2021). Although it seems that the first configuration (all the

\begin{tabular}{llll}
\multicolumn{4}{l}{ Table 2: Characteristics of 230 kV lines } \\
\hline $\begin{array}{l}\text { No. of line } \\
\text { bundles }\end{array}$ & $\begin{array}{l}\text { Maximum } \\
\text { loading (MVA) }\end{array}$ & $\begin{array}{l}\mathrm{R} \\
\left(\mathrm{p} . \mathrm{u} \mathrm{Km}{ }^{-1}\right)\end{array}$ & $\begin{array}{l}\text { R. } \\
(\mathrm{p} . \mathrm{u} \mathrm{Km}\end{array}$ \\
\hline 1 & 397 & $3.85 \mathrm{e}-04$ & $1.22 \mathrm{e}-04$ \\
2 & 794 & $2.84 \mathrm{e}-04$ & $2.44 \mathrm{e}-04$ \\
\hline
\end{tabular}

Table 3: Characteristics of $400 \mathrm{kV}$ lines

\begin{tabular}{|c|c|c|c|}
\hline $\begin{array}{l}\text { No. of line } \\
\text { bundles }\end{array}$ & $\begin{array}{l}\text { Maximum } \\
\text { loading (MVA) }\end{array}$ & $\begin{array}{l}\text { Reactance } \\
\left(\text { p.u Km} \mathrm{Km}^{-1} \text { ) }\right.\end{array}$ & $\begin{array}{l}\text { Resistance } \\
\left(\text { p.u Km}{ }^{-1}\right)\end{array}$ \\
\hline 1 & 750 & $1.24 \mathrm{e}-04$ & $3.50 \mathrm{e}-05$ \\
\hline 2 & 1321 & $9.70 \mathrm{e}-05$ & $7.00 \mathrm{e}-05$ \\
\hline 3 & 1982 & $8.60 \mathrm{e}-05$ & $1.05 \mathrm{e}-04$ \\
\hline
\end{tabular}

Table 4: Construction cost of $230 \mathrm{kV}$

\begin{tabular}{lll}
\hline $\begin{array}{l}\text { No. of line } \\
\text { circuits }\end{array}$ & $\begin{array}{l}\text { Fix cost of line } \\
\text { construction }(\times 103 \text { dollars })\end{array}$ & $\begin{array}{l}\text { Variable cost of line } \\
\text { construction }(\times 103 \text { dollars })\end{array}$ \\
\hline 1 & 546.5 & 45.9 \\
2 & 546.5 & 63.4 \\
\hline
\end{tabular}

Table 5: Construction cost of $400 \mathrm{kV}$

\begin{tabular}{lll}
\hline $\begin{array}{l}\text { No. of line } \\
\text { circuits }\end{array}$ & $\begin{array}{l}\text { Fix cost of line } \\
\text { construction }(\times 103 \text { dollars })\end{array}$ & $\begin{array}{l}\text { Variable cost of line } \\
\text { construction }(\times 103 \text { dollars })\end{array}$ \\
\hline 1 & 1748.6 & 92.9 \\
2 & 1748.6 & 120.2 \\
\hline
\end{tabular}

Table 6: Generation and load arrangements

\begin{tabular}{llllll}
\hline Bus & Load (MW) & Gen. (MW) & Bus & Load (MW) & Gen. (MW) \\
\hline 1 & 378 & 7.15 & 10 & 134 & 0 \\
2 & 202 & 0 & 11 & 125 & 0 \\
3 & 42 & 0 & 12 & 256 & 288 \\
4 & 53 & 0 & 13 & 78 & 101 \\
5 & 45 & 0 & 14 & 46 & 60 \\
6 & 64 & 0 & 15 & 45 & 101 \\
7 & 88 & 0 & 16 & 11 & 0 \\
8 & 49 & 514 & 17 & 14 & 0 \\
9 & 70 & 0 & 18 & 79 & 0 \\
\hline
\end{tabular}


Am. J. Applied Sci., 6 (5): 987-994, 2009

Table 7: Arrangement of lines

\begin{tabular}{lllll}
\hline Corridor & $\begin{array}{l}\text { Length of } \\
\text { corridor }(\mathrm{km})\end{array}$ & $\begin{array}{l}\text { Voltage } \\
\text { level }(\mathrm{kV})\end{array}$ & $\begin{array}{l}\text { No. of } \\
\text { Circuit }\end{array}$ & $\begin{array}{l}\text { No. of } \\
\text { bundle }\end{array}$ \\
\hline $6-1$ & 55 & 2.30 & 1 & 1 \\
$2-1$ & 14 & 2.30 & 2 & 1 \\
$9-6$ & 18 & 2.30 & 1 & 1 \\
$4-2$ & 83 & 230 & 1 & 1 \\
$14-5$ & 110 & 230 & 1 & 1 \\
$11-8$ & 65 & 230 & 2 & 1 \\
$11-10$ & 125 & 230 & 2 & 1 \\
$15-14$ & 139 & 230 & 1 & 1 \\
$12-1$ & 122 & 400 & 1 & 2 \\
$9-5$ & 100 & 230 & 1 & 1 \\
$6-5$ & 103 & 230 & 2 & 1 \\
$13-3$ & 105 & 400 & 1 & 2 \\
$4-3$ & 81 & 230 & 1 & 1 \\
$14-13$ & 44 & 230 & 2 & 1 \\
$12-10$ & 134 & 230 & 2 & 1 \\
$8-1$ & 75 & 230 & 2 & 1 \\
$7-6$ & 33 & 230 & 1 & 1 \\
$7-1$ & 22 & 230 & 1 & 1 \\
$5-16$ & 53 & 230 & 2 & 1 \\
\hline
\end{tabular}

Table 8: First configuration: neglecting the network losses

\begin{tabular}{llll}
\hline Corridor & Voltage level $(\mathrm{kV})$ & No. of circuits & No. of bundle \\
\hline 9-Aug & 230 & 1 & 1 \\
7-Feb & 230 & 1 & 1 \\
5-Jan & 230 & 2 & 2 \\
18-Aug & 230 & 1 & 1 \\
7-May & 230 & 1 & 1 \\
16-Jul & 230 & 1 & 1 \\
6-Mar & 230 & 1 & 1 \\
17-Jul & 230 & 1 & 1 \\
\hline
\end{tabular}

Table 9: Expansion cost of network with the first configuration

Expansion cost of substations

Expansion cost of lines 36.751 million \$US

Total expansion cost of network

36.751 million \$US

Table 10: Expansion cost of network with the second configuration

Expansion cost of substations 20.645 million \$US

Expansion cost of lines 128.817 million \$US

Total expansion cost of network 149.462 million \$US

lines are $230 \mathrm{kV}$ ) is more economic. However, the second configuration is more economic if the network is studied considering the network losses after planning horizon time. The reason is that the annual network losses cost of the first configuration will become large in comparison with the second configuration about 4 years after planning horizon time. Also, the sum of expansion and network losses costs for both configurations is the same at this time. In this method, total expansion cost of the first configuration will become more than the other one after about 4 years from the planning horizon time and subsequently the second configuration will be more economic after this time. Thus, in the second configuration, investment cost is returned after the 4 th year of the expansion time.
Table 11: Second configuration: Considering the network losses

\begin{tabular}{llll}
\hline Corridor & Voltage level $(\mathrm{kV})$ & No. of circuits & No. of bundle \\
\hline $8-9$ & 230 & 2 & 2 \\
$2-8$ & 400 & 2 & 3 \\
$2-7$ & 400 & 1 & 3 \\
$1-5$ & 400 & 2 & 3 \\
$8-18$ & 230 & 2 & 2 \\
$4-5$ & 230 & 2 & 2 \\
$7-16$ & 230 & 1 & 2 \\
$2-5$ & 230 & 2 & 2 \\
$7-17$ & 230 & 1 & 2 \\
$5-11$ & 230 & 1 & 2 \\
$6-13$ & 400 & 2 & 3 \\
$7-13$ & 230 & 1 & 2 \\
$6-9$ & 400 & 1 & 3 \\
$14-15$ & 400 & 1 & 2 \\
$11-18$ & 230 & 1 & 2 \\
\hline
\end{tabular}

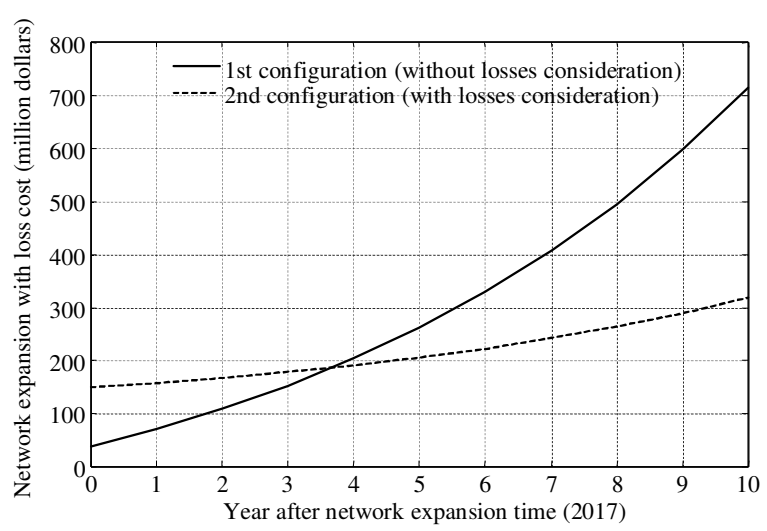

Fig. 4: Sum of expansion costs and annual losses cost of the network with the two proposed configurations

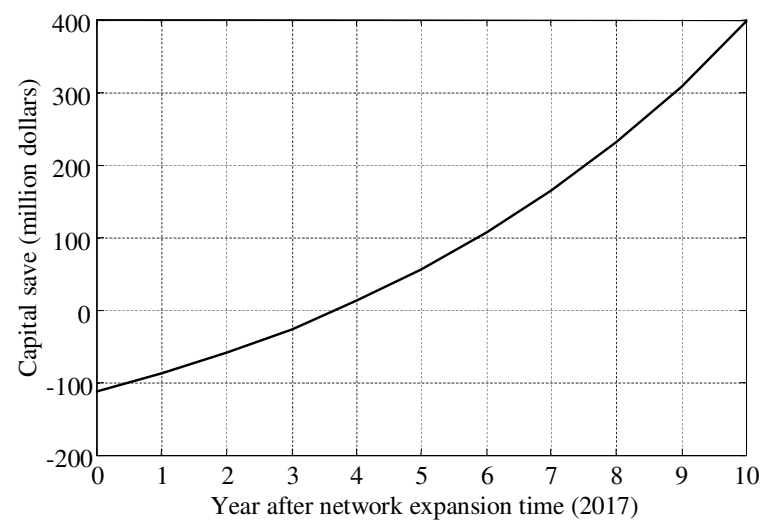

Fig. 5: Investment return curve by choosing of the second configuration in comparison with the first one

It should be noted that although construction cost of $400 \mathrm{kV}$ lines is more than $230 \mathrm{kV}$ lines, but these lines are more economic than $230 \mathrm{kV}$ lines in mid-term 
and long-term, because their losses are less than $230 \mathrm{kV}$ lines. Besides, from the transmitted power through the lines point of view, the second configuration is better, because it is overloaded 13 years after expansion time (planning horizon), whereas the first configuration is overloaded 9 years after expansion time. Moreover, although lines which have 2 or 3 bundle conductors are more expensive than those which have one conductor, these lines increase the network adequacy and decrease the network losses more than lines which have one conductor in each circuits. In addition, construction of these lines prevents useless expansion of lines with one conductor in separate corridors. Due to this fact, in this study, both $400 \mathrm{kV}$ and $230 \mathrm{kV}$ lines have been added to the network with their maximum number of bundle conductors, 2 and 3 , respectively.

\section{CONCLUSIONS}

In this study, the static transmission network expansion planning has been studied using the decimal codification genetic algorithm with various voltage levels and different number of bundle conductors. According to simulation results, it was concluded that the network losses and voltage level of lines play important role in determining of network configuration and arrangement. Moreover, consid-ering voltage level of lines and subsequently the network losses in expansion planning of a network provided the addition of more $230 \mathrm{kV}$ and $400 \mathrm{kV}$ lines to the network. Although expansion cost of the network with considering voltage level and then the network losses increased, total expansion cost of network (the sum of expansion cost of lines and substations and network losses cost) decreased in mid-term and long-term planning due to be less of the network losses. In addition, networks which are expanded by more $400 \mathrm{kV}$ lines were economic in long-term and from transmitted power through the lines point of view was overloaded later. Moreover, it can be seen that although cost of lines which have 2 or 3 bundle conductors is more than those which have 1 conductor, these lines increase the network adequacy and decrease the network losses more than lines of the second type. Also, construction of these lines prevents useless expansion of lines with 1 bundle in separate corridors and optimizes the network expansion planning.

In this study, network losses have been calculated according to DC Load Flow (DCLF). The AC Load Flow (ACLF) using can improve the proposed method because the network losses can be calculated more accurately. Thus, using the ACLF for calculation of the network losses would be our future work in solution of the TNEP problem. Also, hopefully, we would be evaluated the network losses role in dynamic transmission network expansion planning in near future.

\section{REFERENCES}

1. Abdelaziz, R., 2000. Genetic algorithm based power transmission expansion planning. In: Proceedings of the 7th IEEE International Conference on Electronics, Circuits and Systems, pp: 642-645.

2. Levi, V.A. and M.S. Ćalović, 1993. Linearprogramming-based decomposition method for optimal planning of transmission network investments. IEE Proc. Gener. Transm. Distrib., 140: 516-522.

3. Binato, S., G.C. Oliveira and J.L. Araújo, 2001. A greedy randomized adaptive search procedure for transmission expansion planning, IEEE Trans. Power Syst., 16: 247-253.

4. Choi, J., T. Mount and R. Thomas, 2006. Transmission system expansion plans in view point of deterministic, probabilistic and security reliability criteria. In: Proceedings of the 39th Hawaii International Conference on System Sciences, pp: 1-10.

5. Silva, J., M.J. Rider, R. Romero and C.A. Murari, 2005. Transmission network expansion panning considering uncertainness in demand. In: Proceeding of IEEE Power Engineering Society General Meeting, pp: 1424-1429.

6. Binato S., M.V.F. Periera and S. Granville, 2001. A new benders decomposition approach to solve power transmission network design problems. IEEE Trans. Power Syst., 16: 235-240.

7. Garver, L.L., 1970. Transmission net estimation using linear programming. IEEE Trans. Power Apparatus Syst., PAS-89: 1688-1696.

8. Al-Saba, T. and I. El-Amin, 2002. The application of artificial intelligent tools to the transmission expansion problem. Elect. Power Syst. Res., 62: 117-126.

9. Chaturvedi, R., K. Bhattacharya and J. Parikh, 1999. Transmission planning for Indian power grid: A mixed integer programming approach. Int. Trans. Op. Res. 6: 465-482.

10. Contreras, J. and F.F. Wu, 2000. A kernel-oriented algorithm for transmission expansion planning. IEEE Trans. Power Syst., 15: 1434-1440.

11. Gallego, R.A., A. Monticelli and R. Romero, 1998. Transmission system expansion planning by an extended genetic algorithm. IEE Proc. Gener. Transm. Distrib., 145: 329-335.

12. Gallego, R.A., R. Romero and A.J. Monticelli, 2000. Tabu search algorithm for network synthesis. IEEE Trans. Power Syst., 15: 490-495. 
13. Kim, K.J., Y.M. Park and K.Y. Lee, 1988. Optimal longterm transmission expansion planning based on maximum principle. IEEE Trans. Power Syst., 3: 1494-1501.

14. Liu, G., H. Sasaki and N. Yorino, 2001. Application of network topology to long range composite expansion planning of generation and transmission lines. Elect. Power Syst. Res., 57: 157-162.

15. Periera, M.V.F. and L.M.V.G. Pinto, 1985. Application of sensitivity analysis of load supplying capacity to interactive transmission expansion planning. IEEE Trans. Power App. Syst., PAS-104: 381-389.

16. Romero, R., R.A. Gallego and A. Monticelli, 1996. Transmission system expansion planning by simulated annealing. IEEE Trans. Power Syst., 11: 364-369.

17. Romero, R. and A. Monticelli, 1994. A hierarchical decomposition approach for transmission network expansion planning. IEEE Trans. Power Syst., 9: 373-380.

18. Romero, R., A. Monticelli, 1994. A zero-one implicit enumeration method for optimizing investments in transmission expansion planning. IEEE Trans. Power Syst., 9: 1385-1391.

19. Samarakoon, H.M.D.R.H., R.M. Shrestha and O. Fujiwara, 2001. A mixed integer linear programming model for transmission expansion planning with generation location selection. Elect. Power Energy Syst., 23: 285-293.

20. Silva, E.L., H.A. Gil and J.M. Areiza, 2000. Transmission network expansion planning under an improved genetic algorithm. IEEE Trans. Power Syst., 15: 1168-1175.

21. Teive, R.C.G., E.L. Silva and L.G.S. Fonseca, 1998. A cooperative expert system for transmission expansion planning of electrical power systems. IEEE Trans. Power Syst., 13: 636-642.

22. Yen, J., Y. Yan, J. Contreras, M. Pai-Chun and F.F. Wu, 2000. Multi-agent approach to the planning of power transmission expansion. Decision Support Syst., 28: 279-290.

23. Yoshimoto, K., K. Yasuda and R. Yokoyama, 1995. Transmission expansion planning using neurocomputing hybridized with genetic algorithm. IEEE Trans. Power Syst., 126-131.
24. Zhiqi, P., Z. Yao and Z. Fenglie, 2003. Application of an improved genetic algorithm in transmission network expansion planning. In: Proceedings of the 6th International Conference on Advances in Power System Control, Operation and Management, pp: 318-326.

25. Chanda, R.S. and P.K. Bhattacharjee, 1998. A reliability approach to transmission expansion planning using fuzzy fault-tree model. Elect. Power Syst. Res., 45: 101-108.

26. Chanda, R.S. and P.K. Bhattacharjee, 1995. A reliability approach to transmission expansion planning using minimal cut theory. Elect. Power Syst. Res., 33: 111-117.

27. Sohtaoglu, N.H., 1998. The effect of economic parameters on power transmission planning. IEEE Trans. Power Syst., 13: 941-945.

28. Graeber, 1999. Generation and transmission expansion planning in Southern Africa. IEEE Trans. Power Syst., 14: 983-988.

29. Kandil, M.S., S.M. El-Debeiky and N.E. Hasanien, 2000. Rule-based system for determining unit locations of a developed generation expansion plan for transmission planning. IEE Proc. Gener. Transm. Distrib., 147: 62-68.

30. Lee, S.T.Y., K.L. Hocks and H. Hnyilicza, 1970. Transmission expansion of branch and bound integer programming with optimal cost capacity curves. IEEE Trans. Power App. Syst., PAS-93: 1390-1400.

31. Silvestr, D. Braga and J.T. Saraiva, 2005. A multiyear dynamic approach for transmission expansion planning and long-term marginal costs computation. IEEE Trans. Power Syst., 20: 1631-1639.

32. Jalilzadeh, S., A. Kazemi, H. Shayeghi and M. Mahdavi, 2008. Technical and economic evaluation of voltage level in transmission network expansion planning using GA. Energy Conver. Manage., 49: 1119-1125. 